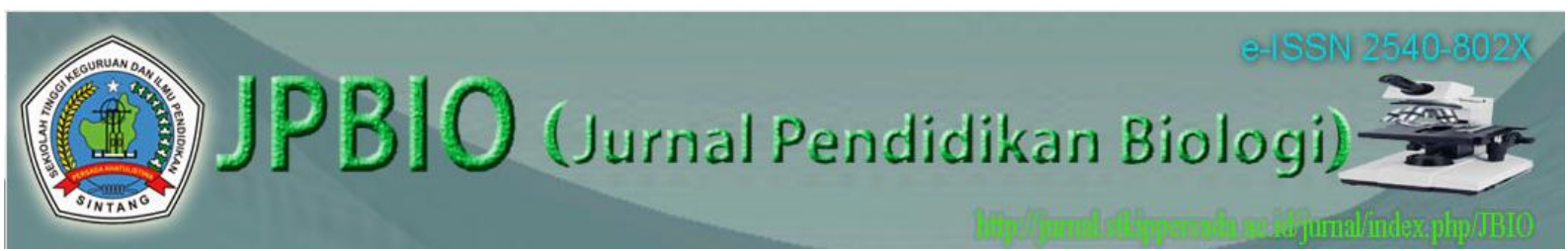

JPBIO (Jurnal Pendidikan Biologi)

Vol. 3 No. 2 November 2018 | $31-40$

ISSN 2540-802x (Online)

DOI: http://dx.doi.org/10.31932/ JPBIO (Jurnal Pendidikan Biologi)

http://jurnal.stkippersada.ac.id/jurnal/index.php/JBIO

\title{
PENGARUH MODEL PEMBELAJARAN KOOPERATIF TIPE COOPERATIVE, INTEGRATED, READING, AND COMPOSITION BERBASIS MEDIA PETA KONSEP TERHADAP KEMAMPUAN BERPIKIR KRITIS SISWA PADA MATERI SISTEM PENCERNAAN MANUSIA
}

\section{Riawaty Dewi ${ }^{1}$, Benediktus Ege $^{2^{*}}$, Didin Syafruddin ${ }^{3}$}

${ }^{1}$ Mahasiswa Program Studi Pendidikan Biologi, STKIP Persada Khatulistiwa, Sintang 2,3Dosen Program Studi Pendidikan Biologi, STKIP Persada Khatulistiwa, Sintang

E-mail: riawatydewi8@gmail.com ${ }^{1}$,ama_tamo@yahoo.com² ${ }^{2}$,didin_saprudin28@yahoo.com³

Diterima: 13 Oktober 2018 Direvisi: 25 Oktober 2018 Disetujui: 10 November 2018

\begin{abstract}
ABSTRAK
Kemampuan berpikir kritis siswa merupakan salah satu indikator keberhasilan belajar. Agar kemampuan berpikir kritis siswa dapat meningkat diperlukan strategi pembelajaran dengan menggunakan model maupun media pembelajaran salah satunya yaitu model pembelajaran CIRC (Cooperative, Integrated, Reading, and Composition) berbasis media peta konsep rantai kejadian. Penelitian ini dilakukan untuk mengetahui pengaruh model CIRC (Cooperative, Integrated, Reading, and Composition) berbasis media peta konsep rantai kejadian terhadap peningkatan kemampuan berpikir kritis siswa kelas VIII SMP Negeri 3 Sintang pada materi sistem pencernaan manusia. Pendekatan dalam penelitian ini berupa pendekatan kuantitatif dengan bentuk penelitian Quasi Eksperimental Design. Populasi pada penelitian ini adalah seluruh siswa kelas VIII SMP Negeri 3 Sungai Tebelian terdiri dari 142siswa. Teknik pengambilan sampel menggunakan teknik purposive sampling dengan total sampel 48 siswa, 24siswa untuk kelas eksperimen dan 24 siswa untuk kelas kontrol. Teknik pengumpulan data menggunakan teknik observasi lansung, teknik pengukuran, dan teknik komunikasi tidak langsung. Instrumen untuk mengukur kemampuan berpikir kritis siswa berupa essay sebanyak 8 item. Berdasarkan uji hipotesis pada posttest kelas eksperimen dan kelas kontrol diperoleh nilai sig. (2-tailed) sebesar 0,00 dan $\alpha=0,05$. Pengujian hipotesis membuktikan bahwa nilai sig. (2-tailed)< $\alpha(0,00<0,05)$ yang artinya $\mathrm{H}_{0}$ ditolak dan $\mathrm{H}_{1}$ diterima, yakni terdapat perbedaan hasil kemampuan berpikir kritis siswa antara kelas eksperimen dan kelas kontrol pada pengukuran akhir posttest.
\end{abstract}

Kata kunci: kemampuan berpikir kritis, CIRC, peta konsep, sistem pencernaan manusia.

\section{ABSTRACT}

Students' critical thinking skill is one of learning success indicators. The students' critical thinking skill can be improved through appropriate strategy learning model or learning media, one of the strategies is CIRC-based media map concept of chain of the events learning model. This research is carried on to know the influence of cooperative learning model type 
CIRC(Cooperative, Integrated, Reading, and Composition) based-media map concept of chain of events toward students' critical thinking skill in human digestive system material in class VIII of SMPN 3 Sintang. This research uses Quantitative approach in the form of quasi experimental design. The population of the research is all students of SMPN 3 Sintang consisted of 142 students, 24 students as experiment class and 24 students as control class. Direct observation, measurement technique, and indirect communication technique are used to collect the data. The instrument used to measure the students' critical thinking skill is essay as many as eight items. Base on hypothesis test in posttest of experiment class and control class as well, obtained sig score. (2-tailed) as 0,00 and $\alpha=0,05$. The hypothesis test proves that sig score. (2-tailed) $<\alpha(0,00<0,05)$ it means $\mathrm{HO}$ rejected and $\mathrm{H1}$ accepted, so there is difference in the results of students' critical thinking skills between the experimental class and the control class at the final posttest measurement.

\section{Keywords: critical thinking skill, CIRC learning model, map concept, critical thinking skill}

\section{PENDAHULUAN}

Pendidikan menjadi kebutuhan bagi setiap manusia. Lembaga pendidikan harus menyediakan pelayanan pendidikan yang baik agar terlahir generasi-generasi muda dengan prestasi yang unggul dan memiliki akhlak dan budi pekerti yang luhur. Selain itu antara interaksi guru dan siswa yang terjadi selama proses belajar mengajar harus berlangsung dengan baik agar mencapai tujuan belajar mengajar yang telah dirumuskan sebelumnya. Kegiatan tersebut dikatakan sebagai kegiatan belajar mengajar bernilai edukatif.

Pendidikan merupakan "suatu rekayasa untuk mengendalikan learning guna mencapai tujuan yang direncanakan secara efektif dan efisien" (Syah, 2009: 10). "Pendidikan merupakan usaha dasar dan terencana untuk mewujudkan suasana belajar dan proses pembelajaran agar peserta didik secara aktif mengembangkan potensi diri, kepribadian, kecerdasan dan akhlak mulia serta keterampilan yang diperlukan dirinya, masyarakat, bangsa dan negara" (Undang-undang No.20 Tahun 2003). Usaha dan keberhasilan belajar dipengaruhi oleh banyak faktor. Faktor-faktor tersebut dapat bersumber pada dirinya atau di luar dirinya atau lingkungannya.

Proses pembelajaran yang dikembangkan di Indonesia sangat menuntut siswa untuk terlibat secara aktif dalam proses kegiatan belajar mengajar sehingga kemampuan pemecahan masalahnya menjadi lebih berkembang. Terkait dengan aspek kemampuan pemecahan masalah dalam pelajaran IImu Pengetahuan Alam Biologi khususnya, maka seorang siswa sangat dituntut untuk memiliki suatu kemampuan berpikir kritis. Berpikir merupakan suatu aktivitas mental yang dilakukan seseorang untuk membantu merumuskan atau memecahkan masalah dan membuat keputusan yang tepat sesuai dengan yang diinginkannya (Johnson, 2007). Situasi juga merupakan hal penting yang harus diperhatikan dalam berpikir kritis karena aktifitas berpikir juga dipengaruhi oleh lingkungan atau situasi yang ada disekitar sehingga kesimpulan juga harus disesuaikan dengan situasi yang sebenarnya. Selain itu, istilah-istilah yang dipakai dalam suatu argumen harus jelas sehingga kesimpulan dapat dibuat dengan tepat dan hal penting terakhir yang harus dilakukan adalah memeriksa secara menyeluruh apa yang sudah ditemukan, dipelajari dan disimpulkan.

Menurut Susanto (2015) upaya untuk pembentukan kemampuan berpikir kritis siswa yang optimal mensyaratkan adanya kelas yang interaktif, siswa dipandang sebagai pemikir bukan seorang yang diajar, dan pengajar berperan sebagai mediator, fasilitator, dan motivator yang membantu siswa dalam belajar bukan mengajar. Menurut Ennis (2011) Berpikir kritis adalah fokus terhadap masalah atau mengidentifikasi masalah dengan baik, mencari tahu apa masalah yang sebenarnya dan bagaimana membuktikannya. Langkah selanjutnya adalah memformulasi argumen-argumen yang menunjang kesimpulan, mencari bukti yang menunjang alasan dari suatu kesimpulan sehingga kesimpulan dapat diterima atau dengan kata lain alasan yang diberikan harus dan sesuai dengan kesimpulan.

Rendahnya kemampuan berpikir kritis siswa dalam pembelajaran IImu Pengetahuan Alam perlu mendapat perhatian serius dari semua kalangan terutama Guru Ilmu Pengetahuan Alam. Guru perlu mengatasi permasalahan yang ada, salah satu caranya dengan 
menerapkan variasi model maupun media pembelajaran yang dapat meningkatkan kemampuan siswa dalam berpikir kritis sehingga mampu memahami materi dan dapat memperbaiki kualitas pembelajaran di kelas, sehingga prestasi belajar siswa dapat meningkat. Upaya meningkatkan kemampuan berpikir kritis siswa dalam mata pelajaran IImu Pengetahuan Alam dapat dibantu dengan menerapkan model pembelajaran kooperatif.

Model pembelajaran kooperatif merupakan salah satu faktor eksternal yang dapat mempengaruhi hasil belajar siswa. Pembelajaran kooperatif tersebut dapat melatih siswa untuk bekerja secara kelompok dan bertanggung jawab terhadap hasil kerja kelompok. Menurut Sanjaya (2010) Pembelajaran kooperatif menekankan pada kesadaran akan keperluan untuk belajar untuk mengaplikasikan pengetahuan, konsep, dan keterampilan yang dimiliki kepada anggota lain dalam kelompoknya.Salah satu model pembelajaran kooperatif yang dapat diterapkan oleh guru adalah CIRC. Cooperative, Integrated, Reading, and Composition (CIRC) adalah pengajaran kooperatif terpadu membaca dan menulis (Ahsan, 2012).

Menurut slavin (2018) Kegiatan pokok dalam CIRC adalah menyelesaikan soal pemecahan masalah meliputi rangkaian kegiatan bersama yang spesifik, yaitu salah satu anggota atau beberapa kelompok membaca soal, membuat prediksi atau menafsirkan isi soal pemecahan masalah (termasuk menuliskan apa yang diketahui, apa yang ditanyakan, dan memisalkan yang ditanyakan dengan suatu variabel), saling membuat ikhtisar/rencana penyelesaian soal pemecahan masalah, menuliskan penyelesaian soal pemecahan masalah secara urut, dan saling merevisi serta mengedit pekerjaan/penyelesaian. Ahsan (2012) berpendapat bahwa langkah-langkah model CIRC dapat diterapkan ke dalam tahap-tahap pelaksanaannya seperti berikut :1) Tahap pertama yaitu orientasi; 2) Tahap organisasi; 3) Tahap pengenalan konsep; 4) Tahap publikasi; 5) Tahap penguatan/refleksi.

Berdasarkan kegiatan pokok dari model CIRC (Cooperative, Integrated, Reading, and Composition) yaitu salah satu anggota kelompok membaca bahan bacaan dan ditanggapi oleh kelompok lain, serta pada tahap pengenalan konsep dan tahap publikasi, dari kegiatan ini dapat memicu siswa untuk berpikir kritis. Model CIRC (Cooperative, Integrated, Reading, and Composition) dalam penelitian ini di kombinasikan dengan media peta konsep rantai kejadian. Media peta konsep rantai kejadian merupakan media yang dapat membantu siswa melihat makna materi pelajaran secara komprehensif dalam setiap komponen konsep-konsep dan mengenali hubungan antara konsep tersebut, hal ini dapat memudahkan proses pembelajaran di sekolah, dan menjadikan pembelajaran lebih bervariasi serta dapat menggali kemampuan berpikir kritis siswa.

\section{METODE PENELITIAN}

\section{Rancangan Penelitian}

Pendekatan dalam penelitian ini adalah pendekatan kuantitatif dengan metode Quasi Experimental Design. Penelitian ini menggunakan desain pretest posttest Nonequivalent Control GroupDesign. Desain ini memiliki dua kelompok yaitu kelompok ekperimen dan kelompok kontrol. Kelompok eksperimen menggunakan model CIRC (Cooperative, Integrated, Reading, and Composition)berbasi media peta konsep rantai kejadian sedangkan kelompok kontrol menggunakan pembelajaran konvensional. Desain pretest posttest Nonequivalent Control GroupDesign dapat dilihat pada Tabel 1.

Tabel1. Pretest Posttest Nonequivalent Control GroupDesign

\begin{tabular}{ccc}
\hline Pretest & Treatment & Posttest \\
\hline $\mathrm{O}_{1}$ & $\mathrm{X}$ & $\mathrm{O}_{2}$ \\
\hline $\mathrm{O}_{3}$ & - & $\mathrm{O}_{4}$ \\
\hline
\end{tabular}

Keterangan :

$\mathrm{O}_{1} \quad=$ Tes awal kelas eksperimen 
$\mathrm{O}_{3} \quad=$ Tes awal kelas kontrol

$\mathrm{O}_{2} \quad=$ Tes akhir kelas eksperimen

$\mathrm{O}_{4} \quad=$ Tes akhir kelas kontrol

$\mathrm{X} \quad=$ Pembelajaran pada kelas eksperimen dengan menggunakan model CIRC.

\section{Populasi dan Sampel Penelitian}

Populasi dalam penelitian ini adalah seluruh siswa kelas VIII SMP Negeri 3 Sintang yang terdiri dari 142siswa dengan total sampel 48 siswa , 24siswa untuk kelas eksperimen yaitu kelas VIII A dan 24 siswa untuk kelas kontrol yaitu VIII B. Penentuan sampel dalam penelitian ini diambil secara Purposive Sampling. Sampel pada penelitian ini diambil berdasarkan pertimbangan dari nilai ulangan semester ganjil.

\section{Instrumen Penelitian}

Instrumen yang digunakan dalam penelitian ini adalah berupa soal test essay sebanyak 10 soal dan angket sebanyak 20 pernyataan. Soal test digunakan untuk mengetahui kemampuan berpikir kritis siswa. Soal test dan angket yang digunakan telah divalidasi oleh tim ahli dan diujicoba untuk melihat validitas dan realibilitas. Hasil ujicoba menunjukkan 8 soal dan 20 item angket valid dan reliabel dengan reliabel 0,75 dengan kategori tinggi.

\section{Prosedur Penelitian}

Prosedur dalam penelitian ini terdiri dari tiga tahap. Tahap pertama adalah tahap pemberian pretest, pemberian pretest untuk melihat kemampuan awal siswa sebelum diterapkan model pembelajaran CIRC (Cooperative, Integrated, Reading, and Composition) berbasis media peta konsep rantai kejadian. Tahap kedua adalah tahap pelaksanaan menggunakan model pembelajaran CIRC (Cooperative, Integrated, Reading, and Composition) berbasis media peta konsep rantai kejadian dalam pembelajaran diterapkan untuk dua kali pertemuan pada materi sistem pencernaan manusia. Kemudian tahap ketiga adalah tahap pemberian posttest, pemberian posttest untuk melihat kemampuan akhir siswa setelah diterapkan model pembelajaran CIRC (Cooperative, Integrated, Reading, and Composition) berbasis media peta konsep rantai kejadian.

\section{HASIL PENELITIAN}

\section{Analisis Data Tes Kemampuan Berpikir Kritis Siswa}

Hasil tes kemampuan berpikir kritis siswa pada penelitian ini dilihat dari pretest dan posttest siswa pada materi sistem pencernaan manusia sesuai dengan model pembelajaran yaitu CIRC (Cooperative, Integrated, Reading and Composition). Penilaian hasil kemampuan berpikir kritis siswa dilakukan pada kelas eksperimen dan kelas kontrol yang bertujuan untuk membedakan hasil belajar menggunakan model pembelajaran CIRC (Cooperative, Integrated, Reading and Composition) dan pembelajaran konvensional. Berikut ini hasil tes kemampuan berpikir kritis dapat dilihat pada Tabel 2 .

Tabel 2. Nilai Pretest dan Postest Kelas Eksperimen dan Kelas Kontrol

\begin{tabular}{lllll}
\hline \multirow{2}{*}{ Nilai } & \multicolumn{2}{c}{ Eksperimen } & \multicolumn{2}{c}{ Kontrol } \\
\cline { 2 - 5 } & \multicolumn{1}{c}{ Pretest } & \multicolumn{1}{c}{ Postest } & Pretest & Posttest \\
\hline Nilai Tertinggi & 65 & 85 & 65 & 65 \\
\hline Nilai Terendah & 50 & 50 & 45 & 40 \\
\hline Rata-rata & 55,20 & 74,37 & 56,04 & 54,37 \\
\hline
\end{tabular}

Berdasarkan Tabel 2 terlihat bahwa nilai rerata pretest siswa kelas eksperimen sebesar 55,20 dengan nilai tertinggi sebesar 65 , nilai terendah sebesar 50 , sedangkan nilai rerata posttest sebesar 73,47 dengan nilai tertinggi 85 , nilai terendah 50 . Pada kelas kontrol diperoleh nilai rerata pretest sebesar 56,04 dengan nilai tertinggi 65 , nilai terendah 45 . Pada posttest diperoleh rerata sebesar 54,37 dengan nilai tertinggi 65 , nilai terendah 40 . 
Dilihat dari hasil indikator kemampuan berpikir kritis menunjukkan hasil yang bervariasi dari masing-masing indikator yaitu pertanyaan terhadap masalah, informasi, konsep, dan interpretasi dan menarik kesimpulan. Adapun rekapitulasi data hasil tes indikator kemampuan berpikir kritis pretest dan posttesst kelas eksperimen dapat dilihat pada Tabel 3 dan Tabel 4

Tabel 3. Nilai Pretest Indikator Kemampuan Berpikir Kritis Siswa Kelas Eksperimen

\begin{tabular}{|c|c|c|c|c|}
\hline \multirow[b]{2}{*}{ No } & \multirow[b]{2}{*}{ Indikator Berpikir Kritis } & \multicolumn{3}{|c|}{ Kelas Eksperimen } \\
\hline & & Skor Diperoleh & $\begin{array}{c}\text { Skor } \\
\text { Maksimal }\end{array}$ & Skor (\%) \\
\hline 1 & $\begin{array}{l}\text { Pertanyaan terhadap } \\
\text { masalah }\end{array}$ & 385 & 600 & 64,17 \\
\hline 2 & Informasi & 335 & 600 & 56,33 \\
\hline 3 & Konsep & 280 & 600 & 46,67 \\
\hline 4 & $\begin{array}{l}\text { Interpretasi dan } \\
\text { menarik kesimpulan }\end{array}$ & 330 & 600 & 55 \\
\hline Juml & & 1.330 & - & 222,17 \\
\hline Nilai & a-rata & 332,5 & - & 55,54 \\
\hline
\end{tabular}

Berdasarkan Tabel 3 terlihat bahwa nilai indikator pertanyaan terhadap masalah pada pretest kelas eksperimen dengan jumlah siswa 24 diperoleh nilai 64,17\%, indikator informasi diperoleh nilai $56,33 \%$, indikator konsep diperoleh nilai $46,67 \%$, sedangkan indikator interpretasi dan menarik kesimpulan diperoleh nilai 55\%.

Tabel 4. Nilai Posttest Indikator Kemampuan Berpikir Kritis Siswa Kelas Eksperimen

\begin{tabular}{lllll}
\hline \multirow{2}{*}{ No } & \multirow{2}{*}{$\begin{array}{c}\text { Indikator Berpikir } \\
\text { Kritis }\end{array}$} & \multicolumn{2}{c}{ Kelas Eksperimen } & \multirow{2}{*}{ Skor (\%) } \\
\cline { 3 - 4 } & & Skor Diperoleh & $\begin{array}{c}\text { Skor } \\
\text { Maksimal }\end{array}$ & \\
\hline 1 & $\begin{array}{l}\text { Pertanyaan } \\
\text { Terhadap Masalah }\end{array}$ & 425 & 600 & 70,83 \\
\hline 2 & Informasi & 475 & 600 & 79,17 \\
\hline 3 & Konsep & 420 & 600 & 70 \\
\hline 4 & $\begin{array}{l}\text { Interpretasi dan } \\
\end{array}$ & 465 & 600 & 77,5 \\
\hline Jumlah & Menarik Kesimpulan & & & 297,5 \\
\hline Nilai rata-rata & 1.785 & - & 74,37 \\
\hline
\end{tabular}

Tabel 5. Nilai Pretest Indikator Kemampuan Berpikir Kritis Siswa Kelas Kontrol

\begin{tabular}{|c|c|c|c|c|}
\hline \multirow[b]{2}{*}{ No } & \multirow[b]{2}{*}{$\begin{array}{c}\text { Indikator Berpikir } \\
\text { Kritis }\end{array}$} & \multicolumn{2}{|c|}{ Kelas Kontrol } & \multirow[b]{2}{*}{ Skor (\%) } \\
\hline & & Skor Diperoleh & $\begin{array}{c}\text { Skor } \\
\text { Maksimal }\end{array}$ & \\
\hline 1 & $\begin{array}{l}\text { Pertanyaan } \\
\text { Terhadap Masalah }\end{array}$ & 380 & 600 & 63,33 \\
\hline 2 & Informasi & 340 & 600 & 56,67 \\
\hline 3 & Konsep & 290 & 600 & 48,33 \\
\hline 4 & $\begin{array}{l}\text { Interpretasi dan } \\
\text { Menarik Kesimpulan }\end{array}$ & 335 & 600 & 55,83 \\
\hline \multicolumn{2}{|c|}{ Jumlah } & 1.345 & - & 224,16 \\
\hline \multicolumn{2}{|c|}{ Nilai Rata-rata } & 336,25 & - & 56,04 \\
\hline
\end{tabular}


Berdasarkan Tabel 4 terlihat bahwa nilai indikator pertanyaan terhadap masalah pada posttest kelas eksperimen dengan jumlah siswa 24 diperoleh nilai 70,83\%, indikator informasi diperoleh nilai $79,17 \%$, indikator konsep diperoleh nilai $70 \%$, sedangkan indikator interpretasi dan menarik kesimpulan diperoleh nilai $77,5 \%$. Adapun rekapitulasi data hasil tes indikator kemampuan berpikir kritis pretest dan posttesst kelas kontrol dapat dilihat pada Tabel 5 dan Tabel 6.

Berdasarkan Tabel 5 terlihat bahwa nilai indikator pertanyaan terhadap masalah pada pretest kelas kontrol dengan jumlah siswa 24 diperoleh nilai $63,33 \%$, indikator informasi diperoleh nilai $56,67 \%$, indikator konsep diperoleh nilai $48,33 \%$, sedangkan indikator interpretasi dan menarik kesimpulan diperoleh nilai 55,83\%.

Tabel 6. Nilai Posttest Indikator Kemampuan Berpikir Kritis Siswa Kelas Kontrol

\begin{tabular}{lllll}
\hline \multirow{2}{*}{ No } & \multirow{2}{*}{$\begin{array}{c}\text { Indikator Berpikir } \\
\text { Kritis }\end{array}$} & \multicolumn{2}{c}{ Kelas Kontrol } & \multirow{2}{*}{ Skor (\%) } \\
\cline { 3 - 4 } & & Skor Diperoleh & $\begin{array}{c}\text { Skor } \\
\text { Maksimal }\end{array}$ & \\
\hline 1 & $\begin{array}{l}\text { Pertanyaan } \\
\text { Terhadap Masalah }\end{array}$ & 260 & 600 & 43,33 \\
\hline 2 & Informasi & 415 & 600 & 69,17 \\
\hline 3 & Konsep & 295 & 600 & 49,17 \\
\hline 4 & Interpretasi dan & 335 & 600 & 55,83 \\
\hline Jumlah & Menarik Kesimpulan & & - & 217,5 \\
\hline Nilai Rata-rata & 1.305 & - & 54,37 \\
\hline
\end{tabular}

Berdasarkan Tabel 6 terlihat bahwa nilai indikator pertanyaan terhadap masalah pada pretest kelas kontrol dengan jumlah siswa 24 diperoleh nilai 43,33\%, indikator informasi diperoleh nilai $69,17 \%$, indikator konsep diperoleh nilai $49,17 \%$, sedangkan indikator interpretasi dan menarik kesimpulan diperoleh nilai 55,83\%.

\section{Hasil Analisis Uji Prasyarat}

a. Hasil Uji Normalitas

Uji Normalitas diperoleh dari hasil pretest dan posttest siswa kelas VIII A sebagai kelas eksperimen dan VIII B sebagai kelas kontrol. Berikut hasil uji normalitas secara umum pada Tabel 7.

Tabel 7. Hasil Uji Normalitas Data Kelas Eksperimen dan Kelas Kontrol.

\begin{tabular}{cllccc}
\multirow{2}{*}{ Kelas } & \multirow{2}{*}{ Jenis tes } & $\bar{x}$ & S & Sig. & $\alpha$ \\
\hline \multirow{2}{*}{ Eksperimen } & Pretest & 55,20 & 5,80 & 0,055 & 0,05 \\
\cline { 2 - 6 } & Posttest & 74,37 & 9,24 & 0,140 & 0,05 \\
\hline \multirow{2}{*}{ Kontrol } & Pretest & 56,04 & 6,07 & 0,118 & 0,05 \\
\cline { 2 - 6 } & Posttest & 54,37 & 6,80 & 0,303 & 0,05 \\
\hline
\end{tabular}

Hasil analisis data pada Tabel 7 menggambarkan hasil pengujian uji normalitas diketahui bahwa data untuk masing-masing tes semuanya berdistribusi normal.

\section{b. Hasil Uji Homogenitas}

Pengujian homogenitas data pretest dan posttest antara kelas eksperimen dan kelas kontrol dianalisis dengan Indepeden Samples Test dengan program SPSS Statistic 18. Hasil 
uji homogenitas pretest dan posttest kelas eksperimen dan kelas kontrol pada dilihat pada Tabel 8.

Tabel 8 Hasil Uji Homogenitas Pretest dan Posttest Kelas Eksperimen dan Kelas Kontrol

\begin{tabular}{cccc}
\hline Jenis tes & $\boldsymbol{\alpha}$ & Sig. & Ket. \\
\hline $\begin{array}{c}\text { Pretest kelas eksperimen } \\
\text { dan kelas kontrol }\end{array}$ & 0,05 & 0,942 & $0,942>0,05$ \\
\hline $\begin{array}{c}\text { Posttest kelas } \\
\text { eksperimen dan kelas } \\
\text { kontrol }\end{array}$ & 0,05 & 0,686 & $0,686>0,05$ \\
\hline
\end{tabular}

Berdasarkan Tabel 8 diperoleh nilai sig untuk Pretest siswa kelas eksperimen dan kelas kontrol sebesar 0,942 >0,05 maka data Pretest homogen dan data Postest kelas eksperimen dan kelas kontrol 0,686 $>0,05$ artinya data Posttest homogen. Jadi, dari hasil pengujian dengan menggunakan SPSSstatistic18 tersebut membuktikan bahwa semua data tes dinyatakan homogen.

\section{c. Hasil Uji Hipotesis}

Pengujian hipotesis dilakukan untuk pengambilan keputusan hipotesis apakah kesimpulan $\mathrm{H}_{\mathrm{o}}$ atau $\mathrm{H} 1$ yang diterima. Setelah dilakukan uji normalitas dan uji homogenitas maka diperoleh data untuk semua data normaliatas berdistribusi normal dan hasil uji homogenitas data homogen untuk nilai pretest dan nilai posttest homogen, maka yang selanjutnya uji hipotesis menggunakan statistik parametrik yaitu Independen Sampel Test mengguankan SPSSStatistic18. hasil uji hipotesis kelas eksperimen dan kelas kontrol dapat dilihat pada Tabel 9.

Tabel 9. Uji Hipotesis

\begin{tabular}{cccc}
\hline Jenis tes & Sig. (2-tailed) & $\alpha$ & Kes. \\
\hline Pretest kedua kelas & 0,629 & 0,05 & Ho diterima \\
\hline Posttestkedua kelas & 0,000 & 0,05 & H1 diterima \\
\hline
\end{tabular}

Tabel 9 menggambarkan hasil uji hipotesis pretest kelas eksperimen dan kelas kontrol dimana diperoleh nilai Sig. (2-tailed) $>$ a yaitu 0,629 > 0,05 maka $\mathrm{H}_{0}$ diterima dan $\mathrm{H}_{1}$ ditolak, yaitu tidak terdapat perbedaan hasil kemampuan berpikir kritis siswa antara kelas eksperimen dan kelas kontrol pada pretest, sedangkan hasil Posttest kelas eksperimen dan kelas kontrol diperoleh nilai Sig. (2-tailed) >a yakni 0,000 $<0,05$ maka $\mathrm{H}_{0}$ ditolak dan $\mathrm{H}_{1}$ diterima, yakni terdapat perbedaan hasil kemampuan berpikir kritis siswa antara kelas eksperimen dan kelas kontrol pada pengukuran akhir (posttest).

\section{Analisis Data Angket Respon Siswa}

Angket siswa diberikan pada siswa kelas eksperimen setelah diberikan perlakuan dengan penggunaan model pembelajaran CIRC CIRC (Cooperative, Integrated, Reading and Composition) berbasis media peta konsep rantai kejadian. Terdapat 20 pernyataan pada angket yang digunakan dalam penelitian ini. Berikut hasil angket respon siswa dapat dilihat pada Tabel 10.

Tabel 10. Hasil Angket Respon Siswa

\begin{tabular}{ccccc}
\hline Kelas & N & Butir Angket & Hasil Angket & Kriteria \\
\hline Eksperimen & 24 & 20 & $80,12 \%$ & "Sangat Kuat" \\
\hline
\end{tabular}




\section{Kemampuan Berpikir Kritis Siswa}

Menurut Halpen dalam Achmad (2007) "Berpikir kritis adalah memberdayakan keterampilan atau strategi kognitif dalam menentukan tujuan". Proses tersebut dilalui setelah menentukan tujuan, mempertimbangkan, dan mengacu langsung kepada sasaranmerupakan bentuk berpikir yang perlu dikembangkan dalam rangka memecahkan masalah, merumuskan kesimpulan, dan membuat kesimpulan dengan efektif dan dalam konteks dan tipe yang tepat.

Sebelum siswa diberikan perlakuan terlebih dahulu guru memberikan tes awal (pretest) pada kelas VIII A sebagai kelas eksperimen dan kelas VIII B sebagai kelas kontrol. Dari hasil (pretest) diperoleh nilai rata-rata 55,20 untuk kelas eksperimen dan 56,04 untuk kelas kontrol. Analisis hasil pretest menunjukkan bahwa tidak terdapat siswa yang memenuhi kriteria ketuntasan minimal (KKM) yaitu 75.

Nilai rata-rata tes akhir (posttest) setelah diberi perlakuan dengan menerapkan model CIRC (Cooperative, Integrated, Reading, and Composition) berbasis media peta konsep rantai kejadian untuk kelas eksperimen diperoleh nilai rata-rata 74,37 dan 54,37 untuk kelas kontrol. Analisis hasil nilai rata-rata posttest kontrol menunjukkan bahwa tidak terdapat siswa yang memenuhi kriteria ketuntasan minimal (KKM) yaitu 75, jika dilihat dari analisis data nilai rata-rata posttest terdapat perubahan nilai siswa dengan meningkatnya nilai posttest dikelas eksperimen.

Kemampuan berpikir kritis siswa antara kelas eksperimen dan kelas kontrol, jika dilihat dari masing-masing indikator juga menunjukkan perbedaan. Nilai tertinggi indikator berpikir kritis kelas eksperimen pada hasil pretest terdapat pada indikator pertanyaan terhadap masalah dengan nilai sebesar $64,17 \%$ dan nilai terendah terdapat pada indikator konsep dengan nilai 46,67\% serta nilai tertinggi posttest terdapat pada indikator informasi dengan nilai sebesar $79,17 \%$ serta nilai terendah terdapat pada indikator konsep dengan nilai sebesar $70 \%$. Adapun pretest di kelas kontrol nilai tertinggi terdapat pada indikator pertanyaan terhadap masalah dengan nilai sebesar $63,33 \%$ dan nilai terendah terdapat pada indikator konsep dengan nilai sebesar $48,33 \%$ serta nilai tertinggi posttest terdapat pada indikator informasi dengan nilai sebesar $69,17 \%$ dan nilai terendah terdapat pada indikator pertanyaan terhadap masalah dengan nilai sebesar $43,33 \%$.

\section{Angket Respon Siswa}

Menurut Sugiyono (2016: 142) "Kuesioner / angket merupakan teknik pengumpulan data yang dilakukan dengan cara memberi seperangkat pertanyaan atau pernyataan tertulis kepada responden untuk dijawabnya". Angket disebarkan setelah melaksanakan tes akhir (posttest). Angket menggunakan skala likert yaitu model checklist $(\sqrt{ })$ pada kolom SS (Sangat Setuju), S (Setuju), RG (Ragu-ragu), TS (Tidak Setuju), dan STS (Sangat Tidak Setuju). Adapun tujuan penyebaran angket/ respon siswa adalah untuk mengetahui respon siswa setelah penerapan model CIRC (Cooperative, Integrated, Reading and Composition) berbasis media peta konsep rantai kejadian. Berdasarkan persentase rekapitulasi jawaban dan tanggapan dari 24 responden yang diberi angket, dapat diketahui bahwa perolehan total ratarata persentase sebesar $80,12 \%$. Berdasarkan hasil tersebut nilai persentase angket respon siswa yang berkriteria "Sangat Kuat".

\section{SIMPULAN}

Berdasarkan analisis data dan pembahasan maka dapat disimpulkan bahwa penggunaan model CIRC (Cooperative, Integrated, Reading and Composition) berbasis media peta konsep rantai kejadian mampu meningkatkan kemampuan berpikir kritis siswa. Berdasarkan hasil penelitian menunjukkan bahwa terdapat perbedaan yang signifikan kemampuan berpikir kritis siswa pada materi sistem pencernaan manusia. Hal tersebut terbukti dengan uji hipotesis yaitu menunjukkan nilai sig. (2-tailed) < nilai $\alpha(0,000<0,05)$.

Adapun saran yang dapat disampaikan yaitu bagi guru, diharapkan mampu untuk mempraktekkan model CIRC (Cooperative, Integrated, Reading and Composition) berbasis media peta konsep rantai kejadian pada pembelajaran IPA sehingga kemampuan berpikir kritis siswa akan lebih meningkat serta bagi peneliti selanjutnya, diharapkan dapat 
menggunakan artikel ini dengan baik sebagai bahan acuan atau pembanding dalam penelitian yang serumpun dengan penelitian ini. Selain itu dapat melakukan penelitian pada sekolah lain dengan memberikan inovasi baru terhadap model CIRC (Cooperative, Integrated, Reading and Composition) berbasis media peta konsep rantai kejadian sehingga kemampuan berpikir kritis siswa dapat meningkat secara maksimal.

\section{UCAPAN TERIMAKASIH}

Peneliti mengucapkan terimakasih kepada Bapak Drs. Rafael Suban Beding, M.Si selaku ketua STKIP Persada Khatulistiwa Sintang yang telah memberikan izin dalam melaksanakan penelitian dan Orangtua yang telah memberikan dukungan dan dana untuk melakukan penelitian serta lbu Raliti,S.Pd. selaku kepala SMP Negeri 3 Sintang dan Ibu Yuliantini, S.T selaku guru biologi yang telah mengijinkan peneliti untuk melakukan penelitian di SMP Negeri 3 Sintang.

\section{REFERENSI}

Dwi, D., Trapsilasiwi, D. \& Fatahillah, A. (2014). Penerapan Peta Konsep (Concept Mapping) Berbasis Resitasi untuk Meningkatkan Aktivitas Dan Hasil Belajar Siswa pada Topik Persegipanjang dan Persegi Kelas VII A SMP Negeri 3 Pasirian Tahun Ajaran 2013/2014.

Jenisa, K., dan Lubis, A. (2016). Penerapan Model Pembelajaran Cooperative Integrated Reading and Composition (CIRC) untuk Meningkatkan Motivasi dan Hasil Belajar Konstruksi Bangunan Siswa Kelas X Tgb Smk Negeri 1 Lubuk Pakam. Jurnal Education Buuilding. Volume 2 Nomor 1 Halaman 80.

Mahmuzah, R. (2015). Peningkatan Kemampuan Berpikir Kritis Matematis Siswa Smp Melalui Pendekatan Problem Posing. Jurnal Peluang. Volume 4 Nomor 1 Halaman 64-66.

Normaya, K. (2015). Kemampuan Berpikir Kritis Siswa dalam Pembelajaran Matematika dengan Menggunakan Model Jucama di Sekolah Menengah Pertama. Edu-Mat Jurnal Pendidikan Matematika. Volume 3 Nomor 1 Halaman 93.

Nuraini. (2017). Strategi belajar peta konsep model rantai kejadian untuk meningkatkan keterampilan menulis cerita pendek berdasarkan cerita pada smp negeri 1 kebonagung kabupaten demak. Jurnal Bangun Rekaprima. Volume 3 Nomor 1 Halaman 38.

Sugiyono. (2016). “Metode Penelitian Kuantitatif, Kualitatif, dan R\&D”. Bandung: Alfabeta.

Sutarno, H., Nurdin, E. A., \& Awalani, A. (2010). Penerapan Model Pembelajaran Cooperative Integrated Reading and Composition (Circ) Berbasis Komputer untuk Meningkatkan Hasil Belajar Siswa pada Pembelajaran Tik. Jurnal Pendidikan Teknologi Informasi dan Komunikasi (PTIK). Volume 3 Nomor 1 Halaman 2.

Suwarna. 2006. Pengajaran Mikro. Yogyakarta: Tiara Wacana Yogya.

Triana. (2016). Pengaruh Metode Discovery Terhadap berpikir kritis siswa pada materi pencemaran lingkungan di kelas VII Sekolah Menengah Pertama Negeri 2 Sintang Tahun Pelajaran 2014/2015. Skripsi tidak diterbitkan. Sintang: STKIP Persada Khatulistiwa.

Trianto. (2011). Model-model pembelajaran inovatif berorientasi konstruktivistik. Jakarta: Prestasi Pustaka. 
Yuliana, D., Walanda, D. K. \& Ratman. (2014). Penerapan Model Pembelajaran Koopeartif Tipe Cooperative, Integrated, Reading and Composition (Circ) pada Materi Struktur Atom Dan Sistem Periodik Unsur Kelas X Sman 1 Pasangkayu. Jurnal Akademika Kimia. Volume 3 Nomor 1 Halaman 52. 